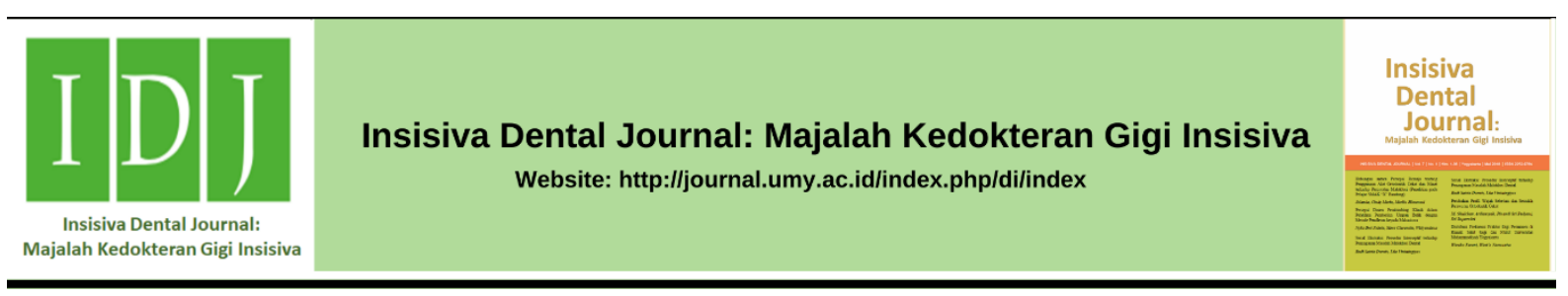

Case Report

\title{
Penatalaksanaan Bedah Periapikal Molar Pertama Maksila pada Instrumen Endodontik Patah
}

Surgical Management of Separated Endodontic Instrument in The Periapical of Maxillary First Molar

\author{
Regia Aristiyanto', Aqilla Tiara Kartikaningtyas ${ }^{2, *}$ \\ ${ }^{1}$ Departemen Konservasi Gigi, Fakultas Kedokteran dan Ilmu Kesehatan, Universitas Muhammadiyah Yogyakarta, Jalan Brawijaya, \\ Tamantirto, Kasihan, Bantul, Indonesia \\ ${ }^{2}$ RSUD Abdul Wahab Sjahranie, Jalan Palang Merah Indonesia, Samarinda, Indonesia
}

Received date: May $22^{\text {nd }}, 2020$; reviewed date: March $24^{\text {th }}, 2021$; revised date: April $8^{\text {th }}, 2021$; accepted date: May $4^{\text {th }}, 2021$ DOI : 10.18196/di.v10i1.8877

\begin{abstract}
Abstrak
Instrumen endodontik patah merupakan salah satu komplikasi yang paling sering terjadi pada perawatan saluran akar. Pengambilan intrumen yang patah dari saluran akar merupakan prosedur yang sulit, terutama ketika menembus hingga periapikal. Laporan kasus ini bertujuan menyajikan penatalaksanaan bedah pengambilan instrumen endodontik patah pada periapikal gigi molar pertama maksila. Seorang pria berusia 29 tahun dirujuk ke departemen konservasi gigi karena mengeluhkan sakit yang tumpul dan intermiten pada gigi molar pertama kiri atas dan bertambah sakit ketika menggigit. Pasien menjelaskan telah menjalani perawatan saluran akar yang tidak lengkap sekitar 2 bulan yang lalu. Pemeriksaan klinis menunjukkan terdapat tumpatan sementara pada permukaan oklusal molar pertama kiri atas dan respon positif pada pemeriksaan perkusi. Berdasarkan pemeriksaan radiograf periapikal, terdapat sebuah segmen file patah yang ekstrusi keluar dari akar mesio bukal dengan obturasi saluran akar yang tidak hermetis pada saluran akar. Pengambilan instrumen patah dilakukan dengan bedah periapikal (teknik retrograde), selanjutnya dilakukan reseksi akar mesiobukal. Penatalaksanaan instrumen endodontik patah hingga daerah periapikal dengan bedah periapikal merupakan pilihan perawatan yang menunjukkan hasil dan prognosis yang baik.
\end{abstract}

Kata Kunci: Instrumen Endodontik Patah; Molar Satu Rahang Atas; Bedah Endodontik; Reseksi Akar

\begin{abstract}
Separated endodontic instrument is one of the most common complication in root canal treatment. Separated instrument removal from root canal is a difficult procedure, especially when the separated instrument extends beyond apex. This case report presents the surgical management of separated endodontic instrument removal from the periapical region the mesiobuccal root of maxillary first molar. A 29-year-old male patient was referred to conservative dentistry department because complained dull intermittent pain and got worse when biting to his maxillary left first molar. Patient gave a history that the patient had undergone incomplete root canal treatment about 2 months ago. Clinical examination showed the presence of temporary filling material on occlusal surface of maxillary left first molar and was symptomatic with positive response on percussion. According to periapical radiograph examination, there was a separated file segment extruding beyond the mesiobuccal root of maxillary left first molar with non-hermetic obturation in root canal. Separated instrument removal was performed use periapical surgery (retrograde technique), then root resection was performed to mesiobuccal root. Management of fractured endodontic instrument beyond the apex by periapical surgery showed favorable result and prognosis.
\end{abstract}

Keywords: Separated Endodontic Instrument; Maxillary First Molars; Endodontic Surgery; Root Resection

* Corresponding author, e-mail: regia230388@gmail.com 


\section{PENDAHULUAN}

Instrumen patah merupakan salah satu komplikasi yang paling sering terjadi selama perawatan saluran akar., $, 2, \underline{3}$ Insidensi yang pernah dilaporkan adalah $0,92 \%$ hingga $4 \%,+, 5,6$, Faktor yang dapat menyebabkan instrumen endodontik patah dalam saluran akar adalah faktor operator, faktor anatomi (akses kavitas, anatomi saluran akar), faktor instrumen (material, desain, proses manufaktur dan eror), serta faktor teknik (teknik instrumentasi, irigasi, penggunaan ulang instrumen). ${ }^{7}$ Prognosis perawatan pada gigi dengan instrumen patah dalam saluran akar tergantung beberapa faktor, yaitu adanya lesi periapikal, adanya mikroba dalam saluran akar saat instrumen patah, serta kualitas obturasi. ${ }^{3}$

Penatalaksanaan terbaik instrumen patah adalah mengeluarkan instrumen patah tersebut agar memungkinkan prosedur debridemen dan obturasi saluran akar yang baik. ${ }^{7}$ Beberapa peralatan dan teknik telah diperkenalkan untuk mengeluarkan instrumen patah dari saluran akar dengan teknik orthograde, $,, 9,10$ namun, pada kondisi klinis tertentu, mengeluarkan intstrumen yang patah dengan teknik orthograde tidak memungkinkan untuk dilakukan, sehingga penatalaksanaan lain yang dapat dilakukan adalah meninggalkan instrumen dalam saluran akar, melakukan bypass atau penatalaksanaan bedah. Keputusan klinis terkait penatalaksanaan instrumen patah dalam saluran akar ditentukan oleh banyak faktor, yaitu panjang instrumen yang patah, tipe dan jenis instrumen, ketebalan struktur dentin, anatomi saluran akar (diameter, panjang dan kurvatur), lokasi gigi dalam lengkung rahang, kondisi jaringan periapikal dan periodontal, tahap preparasi saluran akar saat intrumen patah, lokasi intrumen patah dalam saluran akar, serta faktor pasien. ${ }^{7}$

Pada kasus iatrogenik seperti intrumen patah pada area sepertiga apikal saluran akar dan ekstrusi hingga periapikal, prosedur bedah diindikasikan karena penatalaksanaan pengambilan intrumen patah secara orthograde dapat

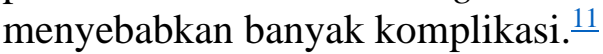

\section{LAPORAN KASUS}

Seorang pria berusia 29 tahun dirujuk ke departemen konservasi gigi karena mengeluhkan sakit yang tumpul dan intermiten pada gigi molar pertama kiri rahang atas dan bertambah sakit jika untuk menggigit. Pasien menjelaskan bahwa pasien telah menjalani perawatan saluran akar sekitat 2 bulan yang lalu, namun perawatan saluran akar tersebut belum selesai. Pemeriksaan klinis menunjukkan terdapat tumpatan sementara pada permukaan oklusal gigi molar pertama kiri rahang atas (gigi 26) dan tidak terdapat pembengkakan pada gingiva di sekitar gigi tersebut. Tes mobilitas dan palpasi negatif, sedangkan tes perkusi positif. Berdasarkan pemeriksaan radiograf periapikal, terdapat sebuah segmen file patah yang ekstrusi keluar dari akar mesiobukal dengan obturasi saluran akar yang tidak hermetis pada saluran akar (Gambar 1). Pasien tidak dicurigai memiliki penyakit sistemik. Berdasarkan pemeriksaan klinis dan radiograf, diagnosis yang ditetapkan adalah previously initiated therapy dengan periodontitis apikalis simtomatik. Rencana perawatan adalah reseksi akar mesiobukal.

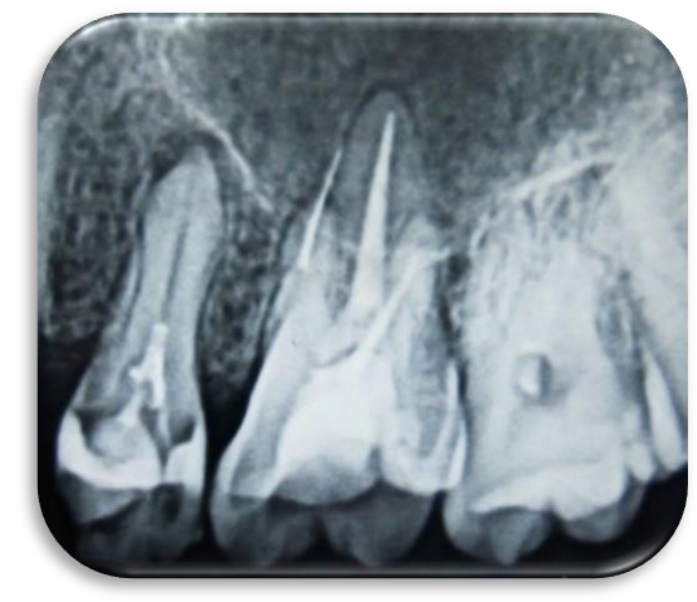

Gambar 1. Radiograf pre-operatif menunjukkan terdapat intrumen endodontik patah pada akar mesiobukal yang ekstrusi hingga periapical 
Gigi 26 dilakukan isolasi dan pembongkaran tumpatan sementara, kemudian dilakukan pengambilan gutta percha pada saluran akar palatal dan distobukal
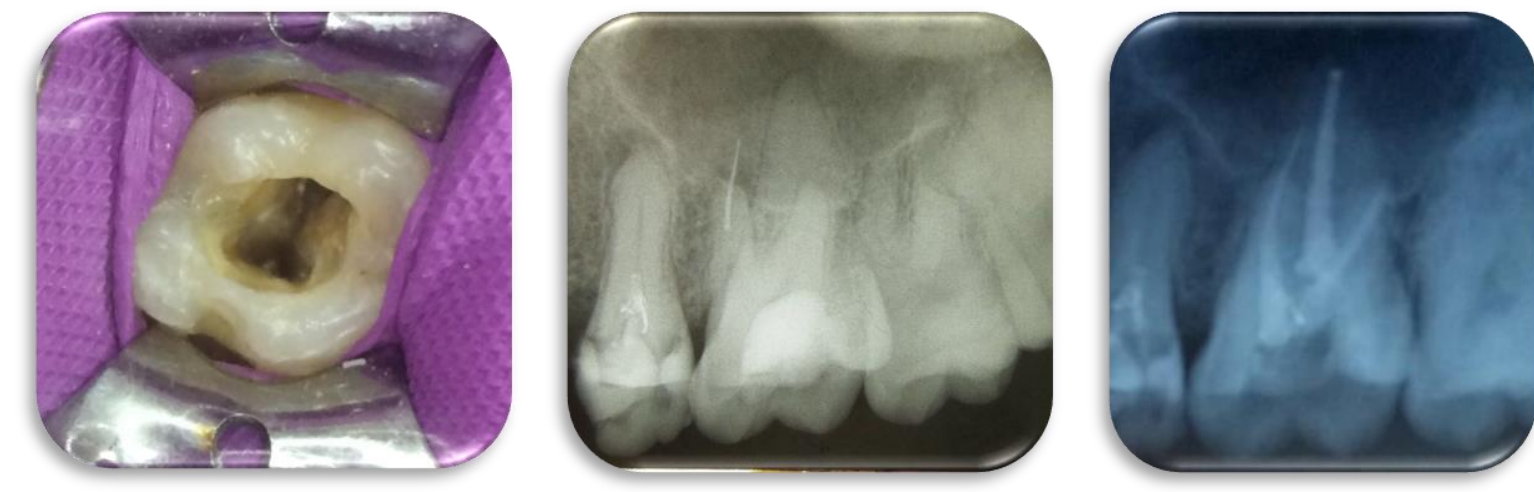

Gambar 2. a) Isolasi, pembukaan akses dan pengambilan gutta percha pada saluran akar; b) Radiograf pasca pengambilan gutta percha; c) Radiograf pasca obturasi saluran akar.

menggunakan file retreatment (Protaper Universal Retreatment File, Dentsply, Switzerland) (Gambar 2a), kemudian dilakukan pemeriksaan radiograf periapikal untuk mengevaluasi pengambilan bahan obturasi pada saluran akar (Gambar 2b). Selanjutnya dilakukan preparasi saluran akar pada saluran akar mesiobukal, distobukal dan palatal menggunakan file rotari (Protaper Next, Dentsply, Switzerland), irigasi saluran akar menggunakan sodium hipoklorit 2,5\% dan EDTA 17\% (Glyde, Dentsply, Switzerland). Medikasi saluran akar menggunakan kalsium hidroksida (UltraCal XS, Ultradent, USA) dan dijadwalkan 1 minggu kemudian untuk kunjungan berikutnya.

Selanjutnya dilakukan obturasi seluruh saluran akar dengan gutta percha dan siler berbasis epoksi resin (AH Plus, Dentsply, Switzerland). Setelah obturasi saluran akar, gigi 26 dilakukan restorasi permanen dengan resin komposit (Filtek Bulk Fill, 3M ESPE, USA) dan pemeriksaan radiograf periapikal (Gambar 2c). Pasien dijadwalkan untuk perawatan reseksi akar mesiobukal.

Pasien menandatangani lembar persetujuan tindakan medis sebelum dilakukan tindakan bedah reseksi akar mesiobukal. Area bedah didisinfeksi dengan iod gliserin, kemudian dilakukan anestesi pada bagian bukal dan palatal area bedah dengan anestesi infiltrasi menggunakan 2\% Lidocaine HCl (Pehacain, Phapros, Indonesia). Selanjutnya pembuatan full thickness semilunarflap menggunakan blade nomor 15 pada mukosa bukal yang menutupi akar mesiobukal (Gambar 3a). Dilanjutkan pengurangan tulang bagian bukal akar mesiobukal dengan bur tulang bentuk bulat menggunakan straight low speed hand piece hingga file patah terlihat (Gambar 3b) dan file yang patah diambil (Gambar 3c), kemudian dilakukan reseksi akar mesiobukal sebanyak $3 \mathrm{~mm}$. Dilakukan preparasi dan obturasi dengan teknik retrograde menggunakan Mineral Trioxide Aggregate (ProRoot MTA, Dentsply, Switzerland). Area bedah dilakukan kuret dan irigasi menggunakan larutan saline steril untuk membersihkan area bedah (Gambar 3d). Selanjutnya aplikasi bone graft (Gamacha, Swayasa Prakarsa, Indonesia) (Gambar 3e) dan flap mukoperiosteal direposisi, kemudian dilakukan penjahitan dengan silk 3.0 nonabsorbable (Silk, OneMed, Indonesia) (Gambar 3f).

Satu minggu pasca bedah, pasien kontrol dan dilakukan evaluasi. Pasien tidak ada keluhan. Pemeriksaan perkusi, palpasi dan mobilitas negatif. Dilakukan hecting aff benang, kemudian irigasi dengan saline steril untuk membersihkan area pasca bedah, kemudian pemeriksaan radiograf untuk 
mengevaluasi perawatan (Gambar 5). Berdasarkan pemeriksaan klinis dan radiograf saat kontrol 1 minggu pasca bedah, perawatan dapat dinyatakan berhasil. Pasien diinstruksikan untuk kontrol secara regular setiap 6 bulan untuk mengevaluasi perawatan dalam jangka panjang.
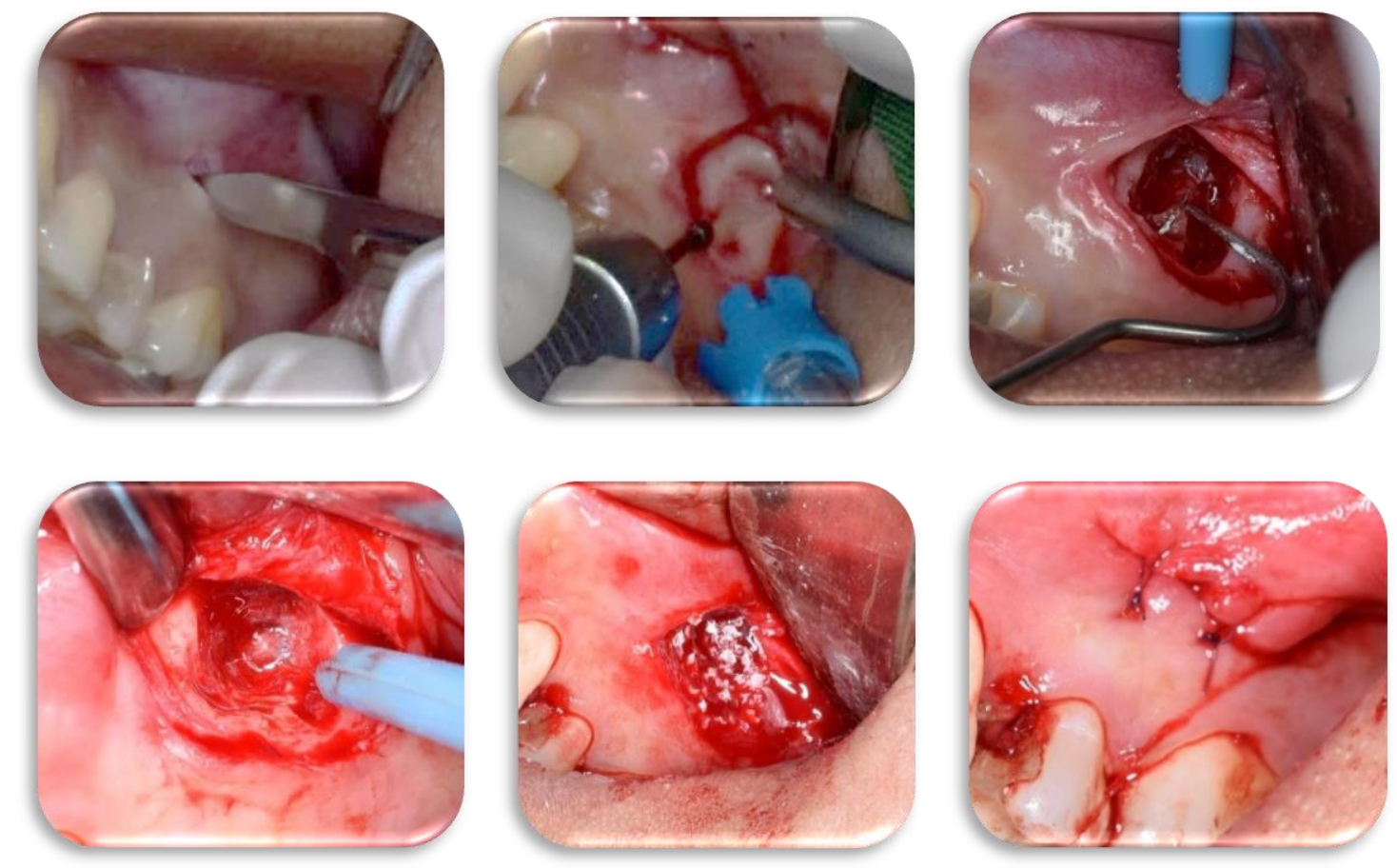

Gambar 3. a) pembuatan fullthickness semilunar flap; b) Pengurangan tulang; c) Pengambilan instrumen patah; d) Kuretase dan irigasi area bedah; e) Aplikasi bone graft; f) Reposisi dan penjahitan flap.

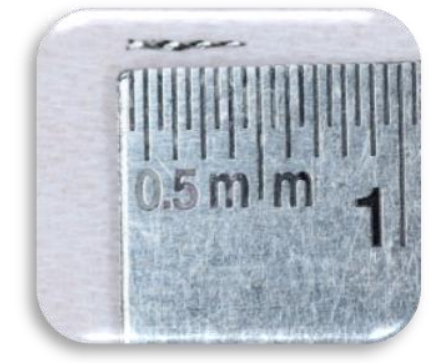

Gambar 4. Instrumen endodontik patah yang telah diambil dari akar mesiobukal gigi 26

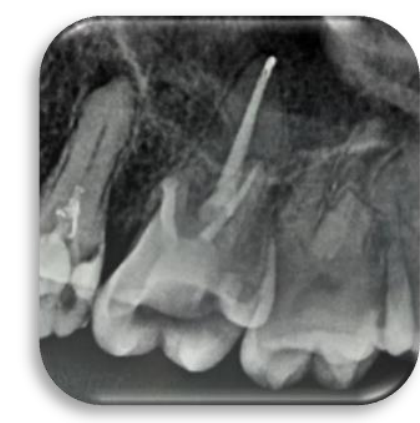

Gambar 5. Radiograf pasca bedah endodontik (reseksi akar) dan pengambilan instrumen endodontik patah

\section{PEMBAHASAN}

Periodontitis apikalis yang persisten pada kasus instrumen endodontik patah dapat disebabkan oleh infeksi persisten di dalam saluran akar yang kompleks dan adanya benda asing yang menimbulkan reaksi inflamasi. $\frac{12}{}$ Adanya instrumen yang patah menghambat akses alat endodontik ke arah apikal dan prosedur disinfeksi saluran akar, sehingga menyebabkan infeksi persisten dalam saluran akar. $\stackrel{3}{\text { Pengambilan }}$ instrumen dari sistem saluran akar merupakan pilihan utama pada kasus intrumen patah karena memungkinkan melakukan prosedur disinfeksi saluran akar yang optimal, sehingga memberikan prognosis yang lebih baik. ${ }^{7}$

Lokasi patahnya instrumen menentukan tingkat kesulitan dan keberhasilan pengambilan intrumen patah. Lokasi sepertiga apikal memiliki tingkat kesulitan yang lebih tinggi dibanding sepertiga tengah atau sepertiga koronal, $, \underline{7}, \underline{13}$ 
sehingga pada kasus tertentu, pengambilan file patah pada sepertiga apikal membutuhkan pendekatan bedah dengan teknik retrograde, terutama pada kasus adanya ekstrusi instrumen patah ke periapikal. $\stackrel{14}{ }$ Pertimbangan teknis pemilihan tindakan bedah endodontik pada kasus instrumen patah di sepertiga apikal dan ekstrusi ke arah apikal adalah tingkat kesulitan atau kegagalan jika pengambilan instrumen dilakukan secara orthograde, sedangkan pertimbangan biologis pemilihan tindakan bedah endodontik adalah adanya benda asing yang dapat memicu respon inflamasi. $\underline{15}$

Jenis bedah endodontik telah banyak dilaporkan, seperti replantasi intensional, hemiseksi, reseksi akar dan bedah periapikal. Tidak ada prosedur bedah endodontik yang diindikasikan khusus untuk sebuah situasi klinis karena terdapat beberapa faktor yang harus dievaluasi untuk menentukan jenis bedah endodontik yang sesuai, seperti faktor anatomi, lokasi instrumen patah dalam saluran akar, adanya penyakit periapikal, kondisi jaringan periodontal, serta pengalaman operator dan kelengkapan alat. ${ }^{7}, \underline{16}$ Pada kasus reseksi akar, pemotongan sebanyak $3 \mathrm{~mm}$ dinyatakan cukup untuk menghilangkan ramifikasi dan saluran akar lateral terinfeksi. $\stackrel{15}{-}$ Aplikasi root-end filling material pasca reseksi akar berfungsi untuk mencegah infeksi ulang dari jaringan periapikal. ${ }^{17}$ Penggunaan MTA sebagai root-end filling material telah dilaporkan memiliki hasil yang baik. $\underline{18, \underline{19}}$

\section{KESIMPULAN}

Penatalaksanaan pengambilan instrumen endodontik patah hingga periapikal dengan bedah periapikal (teknik retrograde) merupakan pilihan perawatan yang menunjukkan hasil dan prognosis yang baik.

\section{DAFTAR PUSTAKA}

1. Avoaka-Boni MC, Désiré Kaboré W, Gnagne-Koffi Y, Djolé S, Kouadio K. Frequency of complications during endodontic treatment: A survey among dentists of the town of Abidjan. Saudi Endod J. 2020;10(1): 45-50.

2. Ali SA, Hussain M, Shahzad M, Nafees H. Frequency of procedural errors during root canal treatment performed by house officers in private teaching dental hospital. J Liaquat Univ Med Heal Sci. 2019;18(1): 55-9.

3. Vouzara T, Chares M el, Lyroudia K. Separated Instrument in Endodontics: Frequency, Treatment and Prognosis. Balk J Dent Med. 2018; 22(3): 123-32.

4. Akhtar S, Siddiqui F, Sheikh A, Rashid $S$, Khurshid Z, Najeeb $S$, et al. Frequency of Procedural Errors during Root Canal Treatment Performed by Interns. Br Biotechnol J. 2016;12(1):18.

5. Caballero-Flores $\mathrm{H}$, Nabeshima CK, Binotto E, Machado MEL. Fracture incidence of instruments from a singlefile reciprocating system by students in an endodontic graduate programme: a cross-sectional retrospective study. Int Endod J. 2019;52(1):13-8.

6. Machado R, de Souza C, Colombelli MF, Picolli AP, Junior JS, Cosme-Silva $\mathrm{L}$, et al. Incidence of ProTaper universal system instrument fractures - A retrospective clinical study. Eur Endod J. 2018;3(2):77-81.

7. Rambabu T. Management Of Fractured Endodontic Instruments In Root Canal: A Review. J Sci Dent. 2014;4(2):40-8.

8. Bürklein S, Donnermeyer D, Wefelmeier M, Schäfer E, Urban K. Removing fractured endodontic NiTi instruments with a tube technique: Influence of pre-treatment with various agents on adhesive forces in vitro. Materials (Basel). 2020;13(1):8-15.

9. Gupta R, Sharma T, Charles N, Bedi R. Clinical Approach To the Management of Fractured Instruments Using Ultrasonics and the Instrument Retrieval System Under the Dental Operating 
Microscope. Int J Med Biomed Stud. 2020;4(3):116-21.

10. Yang Q, Shen Y, Huang D, Zhou X, Gao $Y$, Haapasalo M. Evaluation of Two Trephine Techniques for Removal of Fractured Rotary Nickel-titanium Instruments from Root Canals. J Endod. 2017;43(1):116-20.

11. Setzer FC, Karabucak B. Surgical endodontics. Essent Endodontology Prev Treat Apical Periodontitis. 2019;345-85.

12. Nair PNR. On the causes of persistent apical periodontitis: A review. Int Endod J. 2006;39(4):249-281.

13. McGuigan MB, Louca C, Duncan HF. Clinical decision-making after endodontic instrument fracture. Br Dent J. 2013;214(8):395-400.

14. Sheethi KV, Sheoran K, Singh TV. Surgical removal of fractured endodontic instrument extending beyond the periapex of mesiobuccal root of maxillary second molar through the maxillary sinus. J Clin Diagnostic Res. 2017; 11(10):ZD04-5.

15. Ruddle CJ. Surgical endodontic retreatment. J Calif Dent Assoc. 1991;19(5):61-67.

16. Chopra S, Bansal P, Bansal P. Essix Appliance- An Innovation Modification for use as Temporary Bridge- A Case Report. J Adv Med Dent Scie Res. 2020; 8(1):184-6.

17. Bansode P V, Pathak SD, Wavdhane MB, Khedgikar SB, Sakharkar R. Retrograde Root End Filling Materials. 2016; 15(11):60-4.

18. Shetty S, Hiremath G, Yeli M. A comparative evaluation of sealing ability of four root end filling materials using fluid filtration method: An in vitro study. J Conserv Dent. 2017;20(5): 307-10.

19. Hosoya N, Takigawa T, Horie T, Maeda $\mathrm{H}$, Yamamoto $\mathrm{Y}$, Momoi $\mathrm{Y}$, et al. A review of the literature on the efficacy of mineral trioxide aggregate in conservative dentistry. Dent Mater J. 2019; 38(5):693-700. 